Tropical Journal of Pharmaceutical Research July 2014; 13 (7): 1179-1190

ISSN: $1596-5996$ (print); 1596-9827 (electronic)

(C) Pharmacotherapy Group, Faculty of Pharmacy, University of Benin, Benin City, 300001 Nigeria.

All rights reserved.

Available online at http://www.tjpr.org

Review Article

http://dx.doi.org/10.4314/tjpr.v13i7.24

\title{
Biodegradable Poly(D,L-lactic-co-glycolic acid)-Based Micro/Nanoparticles for Sustained Release of Protein Drugs - A Review
}

\author{
Rezaul H Ansary, Mohamed B Awang and Mokhlesur M Rahman* \\ Kulliyyah of Pharmacy, International Islamic University Malaysia, 25200 Kuantan, Malaysia
}

*For correspondence: Email: mdrahman@iium.edu.my

Received: 10 July 2013

Revised accepted: 16 April 2014

\begin{abstract}
Biodegradable poly(D, L-lactide-co-glycolide) (PLGA) and PLGA-based polymeric nanoparticles are widely used for sustained release of protein and peptide drugs. These formulations are usually prepared by water/oil/water (W/O/W) and solid/oil/water (S/O/W) double emulsion solvent evaporation method. Other methods of preparation are nanoprecipitation, emulsion solvent diffusion and salting-out. This review attempts to address the effects of PLGA molecular weight, lactide to glycolide ratio, crystallinity, hydrophilicity as well as nanoparticles preparation variables (e.g., homogenizer speed, surfactants nature and concentration) on the size, morphology, drug encapsulation efficiency and release profile of PLGA mico/nanoparticles. The current knowledge of protein instability during preparation, storage and release from PLGA micro/nanoparticles and protein stabilization approaches has also been discussed in this review.
\end{abstract}

Keywords: Poly(D, L-lactic-co-glycolic acid), Nanoparticles, Microparticles, Protein/peptides, Sustained release, Protein instability

Tropical Journal of Pharmaceutical Research is indexed by Science Citation Index (SciSearch), Scopus, International Pharmaceutical Abstract, Chemical Abstracts, Embase, Index Copernicus, EBSCO, African Index Medicus, JournalSeek, Journal Citation Reports/Science Edition, Directory of Open Access Journals (DOAJ), African Journal Online, Bioline International, Open-J-Gate and Pharmacy Abstracts

\section{INTRODUCTION}

Biodegradable polymeric nanoparticles are solid or semisolid colloidal particles ranging in size from 10 to $1000 \mathrm{~nm}$ [1]. They consist of both micro-and macromolecular substances and can be used as drug carriers. The drug can be adsorbed, dissolved, entrapped, or encapsulated into the nanoparticles matrix. In conventional administration, macromolecular drugs such as protein and peptide drugs are administered by daily, sometimes multiple injections via a parenteral route due to their short half life in vivo. To improve patient compliance and convenience, controlled release formulations of protein and peptide drugs have been developed [2-4].
Over the past three decades, poly(D, L-lactic-coglycolic acid) (PLGA) has been investigated extensively for developing micro/nanoparticles for controlled release of protein and peptide drugs due its biodegradability and biocompatibility [5-7]. An ideal micro/nanoparticle formulation is one which should have high encapsulation efficiency, loading capacity, sustained and complete release of the encapsulated drug with retained structural integrity $[8,9]$. High protein loading and high encapsulation efficiency are very important due to the extremely high price of pharmaceutical proteins. Several protein and peptide -PLGA microspheres are currently available in the United States and European markets, although 
they still present various challenges for researchers.

In general, the major drawbacks in the development of PLGA based micro/nanoparticle formulations in protein and peptide $\mathrm{d}$ delivery are the high initial burst, incomplete release and instability of the encapsulated proteins [10-12]. Initial burst release means the rapid release of a large amount of encapsulated protein. This phenomenon is commonly observed in PLGA based micro/nanoparticles delivery system. This is due to the rapid diffusion of protein molecules adsorbed or located at the surface of the PLGA micro/nanoparticles. A great amount of the loaded protein is not released after a certain period of release study either due to protein aggregation or adsorption to the strong hydrophobic PLGA surfaces resulting in incomplete protein release. As a result of the degradation of PLGA during the drug release process, lactic and glycolic acids are generated, thereby resulting in a significant reduction of the $\mathrm{pH}$ of the microenvironment and denaturation of the encapsulated proteins [13,14]. The release kinetics of encapsulated protein and peptide drugs from PLGA micro and nanoparticles depend on a number of factors such as PLGA molecular weight, lactide/glycolide ratio, PLGA end groups, particle morphology, drug distribution, etc $[15,16]$. This review addresses current knowledge on the preparation of PLGAbased micro/nanoparticles for parenteral and oral delivery of protein and peptide drugs with particular emphasis on the retention of biological activity of encapsulated drugs.

\section{APPLICATIONS OF PLGA IN CONTROLLED RELEASE FORMULATIONS}

\section{Method of preparation and properties}

Among the different classes of biodegradable polymers, poly(D,L-lactide-co-glycolide) (PLGA) and its homopolymers poly(lactide) (PLA) and poly(glycolide) (PGA) are the most widely used biodegradable polymers. These polymers have been approved by the United States Food and Drug Administration (FDA) for drug delivery due to their excellent biocompatibility, biodegradability and mechanical strength [5]. They can degrade by non-enzymatic hydrolysis of the ester backbone in body fluid. The degradation products (i.e. lactic and glycolic acids) are metabolic compounds and readily eliminated from the body through Krebs cycle [6]. Due to these characteristics, these polymers have the advantage of not requiring surgery for removal from the body after they have served their purposes. They protect the entrapped drug against degradation and control its site specific release. PLGA is synthesized through ringopening polymerization of two different monomers, the cyclic dimers (1, 4-dioxane-2, 5diones) of glycolic acid and lactic acid. During polymerization, successive monomeric units (of glycolic or lactic acid) are linked together in PLGA by ester linkages, thus yielding a linear, aliphatic polyester as a product [7]. The poly(D, L-lactide-co-glycolide) synthetic scheme is described in Figure 1.

\section{Effect of PLGA properties on drug release}

With varying the ratio of lactide to glycolide, amorphous and crystalline forms of PLGA can be obtained. It has been found that the time required for hydrolytic degradation of PLGA is related to the lactide to glycolide ratio, end group (ester or free carboxyl group) and molecular weight of polymer. As the most frequently used biodegradable polymer for drug loaded microsphere/nanospheres preparation, the effect of different PLGA properties such as molecular weight, lactide/glycolide ratio, and the end group capping on drug release have been extensively studied. Low molecular weight PLGA generally leads to a faster polymer degradation and a more rapid drug release $[17,18]$. As lactide is more hydrophobic than glycolide, an increase in lactide content in PLGA copolymers decreases the polymer degradation rate and results in a slower drug release [19]. The end group of PLGA is a factor that affects the hydrophilicity of the polymer. In general, PLGA copolymers carrying free carboxylic end groups caused a high initial burst and release rates compared to the endcapped polymer [20]. Uncapped PLGA with free carboxyl termini is more hydrophilic and absorb more water, leading to a higher degradation rate than its end-capped species with esterified carboxyl termini [21]. Thus, the physical and chemical characteristics of PLGA such as molecular weight, copolymer ratio, ester or free carboxyl end groups and glass transition temperature are important factors for the biodegradability of the polymers.

PLGA of varying molecular weight (ranging from 10 to $>100 \mathrm{kDa}$ ) and different lactide to glycolide molar ratios $(50: 50,65: 35,75: 25$, and $85: 15)$ is available on the market. Normally, 50:50 lactide/glycolide PLGA copolymers have the fastest half-life of degradation, around 50-60 days, whereas $65: 35,75: 25$, and $85: 15$ lactide/glycolide copolymers have progressively longer degradation half-lives in vivo. 
<smiles>CC(O)C(=O)O</smiles>

lactic acid<smiles>CC(C)OC(=O)C(C)OC(=O)O</smiles><smiles>O=C(O)CO</smiles>

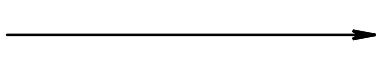<smiles>O=C1COC(=O)CO1</smiles>

glycolic acid<smiles>CCC(C)(O)C(=O)C(C)OC(C)(CC)C(C)(C)C(=O)COC(C)(C)O</smiles>

Poly(lactide-co-glycolide)

Fig 1: Pol(D, L-lactide-co-glycolide) (PLGA) synthetic schemes

Table 1 exhibits some physical properties of different PLGA. The half-life of these polymers can be decreased or increased by co-blending with more hydrophilic or hydrophobic compounds such as polyethylene glycol or polycaprolactone. Visscher et al studied the biodegradation of poly(D,L-lactide) and 50:50 poly(D,L-lactide-coglycolide) in rat gastrocnemius muscles $[22,23]$. Poly(D,L-lactide) nanoparticles was completely degraded within 480 days, whereas the PLGA nanoparticles was degraded in 63 days. This happened due to more hydrophilic and semicrystalline nature of the glycolide part. Thus, PLGA with 50:50 lactide to glycolide ratio is more advantageous than other polymers due to its fastest degradation rate and thus resulting in a faster drug release from the nanoparticles.

Glass transition temperature ( $\mathrm{Tg})$ is the temperature at which the polymers change from glassy state to rubbery state. At this point, the mechanical behavior of the polymer changes from rigid and brittle to tough and leathery (plastic behavior). The Tg of PLGAs is commonly above the physiological temperature of $37{ }^{\circ} \mathrm{C}$, which gives them enough mechanical strength to be fabricated into delivery devices. The $\mathrm{Tg}$ of the PLGA decreases with decrease of lactic acid content in copolymer and with decrease in their molecular weight [24].

Microspheres and nanospheres based on PLGA have been extensively investigated for sustained and targeted release of drugs such as anticancer drugs [25], antibiotics [26-28], peptide and protein drugs namely human growth hormone [29], leuprolide acetate [30], octreotide [31], lysozyme [32], bovine serum albumin (BSA) [33] and insulin [34].

Table 1: Physical properties of some PLGAs

\begin{tabular}{llllll}
\hline $\begin{array}{l}\text { Polymer } \\
\text { (lactide to } \\
\text { glycolide ratio) }\end{array}$ & $\begin{array}{l}\text { Inherent } \\
\text { viscosity } \\
\text { (dL/g) }\end{array}$ & Physical state & $\begin{array}{l}\text { Glass } \\
\text { transition temp } \\
\left({ }^{\circ} \mathbf{C}\right)\end{array}$ & $\begin{array}{l}\text { Solvent } \\
\text { solubility* }\end{array}$ & $\begin{array}{l}\text { Approx. } \\
\text { degradation } \\
\text { time (months) }\end{array}$ \\
\hline PLGA (50:50) & $0.55-0.75$ & Amorphous & $45-50$ & $1,2,3,4,5,6$ & $1-2$ \\
\hline PLGA (65:35) & $0.55-0.75$ & Amorphous & $45-50$ & $1,2,3,4,5,6$ & $3-4$ \\
\hline PLGA (75:25) & $0.55-0.75$ & Amorphous & $50-55$ & $1,2,3,4,5,6$ & $4-5$ \\
\hline PLGA (85:15) & $0.55-0.75$ & Amorphous & $50-55$ & $1,2,3,4,5,6$ & $5-6$ \\
\hline $\begin{array}{l}\text { 1 = acetone, 2 } \\
\text { dichloromethane }\end{array}$
\end{tabular}




\section{FUNCTIONAL ALIPHATIC POLYESTERS FOR NANOPARTICLE PREPARATION}

Most polyesters do not have significant number of functional groups that could enhance their potential applications. Recently, extensive work has been carried out towards functionalizing polyesters in order to enhance the drug delivery behavior of the synthesized nanoparticles. The introduction of functional pendant groups in side chains along the polymer backbone can be used to alter the key properties of these polyesters. Functional aliphatic polyesters can be synthesized by two different synthetic methods (1) the functionalization of pre-formed PLGA, and (2) the polymerization of functionalized monomers/dimers. Practically, the second protocol is preferred, due to the risk of side reactions (e.g. chain scission and racemization) associated with the first protocol. The polymerization of functionalized mono/dimers can generally be conducted via: (i) polycondensation, (ii) ring-opening polymerization (ROP), or (iii) enzymatic polymerization. Ring opening polymerization (ROP) is often preferred method. Since, high molecular weight polymers can be obtained easily in a controlled manner in contrast to the other two methods.

A variety of functionalized polyesters containing different types of side chains and end groups have been synthesized in recent years [35-37]. An interesting type of functionalized polyester, poly(lactic-co-hydroxymethyl glycolic acid) (PLHMGA) has been synthesized by Hennink and co-workers [38,39]. This functionalized polymer (Figure 2) containing side chains with free $\mathrm{OH}$ groups are more hydrophilic than conventional PLGA. The introduction of $\mathrm{OH}$ groups provide polymers with tunable degradation behavior by suppression of crystallinity and enhanced hydrophilicity which improve cell adhesion. Thus, an increased hydrophilicity results in a greater water uptake capacity of the polymers, thereby increasing the degradation rate of the polymers.

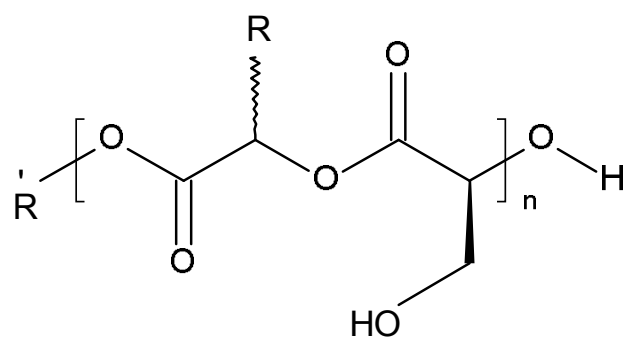

Figure 2: Functionalized poly(lactic-co-hydroxymethyl glycolic acid) (PLHMGA) polymer

\section{PREPARATION OF DRUG LOADED POLY-MERIC NANOPARTICLES}

Several methods have been developed to prepare drug loaded micro and nanoparticles with desired release characteristics from biodegradable polymers. These include: emulsification solvent evaporation [40], nanoprecipitation [41], emulsification solvent diffusion method [42] and salting out [43]. The use of a particular method in the preparation of drug loaded nanoparticles depends on the nature of the polymer employed, nature of the drug to be encapsulated, intended use of the system, and intended duration of the therapy. In vitro and in vivo responses from the nanoparticles are influenced by their various properties, such as the particle size and size distribution, surface morphology, porosity, surface chemistry, surface adhesion, zeta-potential, drug stability, drug encapsulation efficiency, surface/bulk erosion/degradation, diffusion of the drug, kinetics of drug release, and the thermodynamic properties of the nanoparticles.

Depending on the preparation methods drugs or antigens can either be entrapped in the polymer matrix, encapsulated in a liquid core, surrounded by a shell-like polymer membrane, or bound to the particle surface by adsorption [44]. For drug loading into nanoparticles, three major strategies can be employed: (1) covalent attachment of the drug to the particle surface or to the polymer prior to preparation, (2) adsorption of the drug to a preformed carrier system, and (3) incorporation of the drug into the particle matrix during particle preparation [45]. The release rates of nanoparticles depend upon: (i) desorption of the surface-bound/adsorbed drug, (ii) diffusion through the nanoparticle matrix, (iii) diffusion (in case of nanocapsules) through the polymer wall, (iv) nanoparticle matrix erosion, and (v) a combined erosion/diffusion process. During these preparation and release processes, the bioactivity of therapeutic agents must be remained in native form.

\section{Emulsification-solvent evaporation method}

There are single $(\mathrm{O} / \mathrm{W})$ and double $(\mathrm{W} / \mathrm{O} / \mathrm{W})$ emulsion systems in this fabrication method. Single emulsion method is conducted for the formulation of hydrophobic drugs (oil soluble); while double emulsion is adopted for the encapsulation of hydrophilic drugs (peptide and protein drugs). 


\section{Water/oil/water (W/O/W) double emulsion solvent evaporation method}

The W/O/W double emulsion solvent evaporation method has been widely used due to its relatively simple process, convenience in controlling process parameters, and ability to produce with inexpensive instrument [46]. In this method, the polymer is first dissolved in a water-immiscible, volatile, organic solvent. Usually, dichloromethane (DCM) is selected as organic solvent, but other solvents like chloroform, ethyl acetate or methylethyl ketone have also been investigated. An aqueous solution of hydrophilic drug is added to this polymer solution and the mixture is emulsified by a high speed homogenizer or a sonicator to form the first $\mathrm{W} / \mathrm{O}$ emulsion. Then, the primary $\mathrm{W} / \mathrm{O}$ emulsion is further added gently with stirring into a large volume of outer water phase containing surfactant, such as poly(vinyl alcohol) (PVA), resulting in a $\mathrm{W} / \mathrm{O} / \mathrm{W}$ double emulsion.

The selection of surfactants in the outer water phase is an important factor for successful nano or microparticles fabrication. The aggregation of PLGA particles during the process of particle formation is a major problem regardless of the fabrication method. In order to prevent the aggregation of PLGA particles, polymer stabilizers are often used. Furthermore, the size and shape of the particles can also be influenced by the stabilizer used.

Surfactants or stabilizers are amphiphilic molecules that posses both hydrophilic and hydrophobic parts. The hydrophilic moiety is called the head and the hydrophobic part the tail. The head can be charged or uncharged polar group. Depending on the nature of head groups, different kinds of surfactants such as non-ionic surfactant poly(vinyl) alcohol (PVA) [47], anionic surfactant sodium dodecyl sulphate (SDS) [48], cationic surfactant didodecyl dimethyl ammonium bromide (DMAB) [49], and amphiphilic surfactant d-a-tocopheryl polyethylene glycol 100 succinate vitamin E (TPGS) [50] are commonly applied based on emulsion systems.

To harden the nanoemulsion droplets into solid nanoparticles, the organic solvent is removed by either solvent extraction or solvent evaporation and the nanoparticles are collected by filtration or centrifugation. For the removal of solvent, the stirring process may be continued for several hours at high-temperature/low-pressure conditions. The properties of nanoparticles such as drug loading capacity (LC), encapsulation efficiency (EE), release profiles and morphology (shape and size) depend on various parameters such as drug (type and concentration), polymer (composition, molecular weight, and concentration), volume ratio between drug and polymer solution, emulsification method (homogenization time and speed), surfactant (types and concentration) additives in the internal water phase and external water phase (e.g., $\mathrm{NaCl}, \mathrm{NaHCO}_{3}$, sucrose ) [51-53].

Bilati et al [15] investigated the effect of polymer type on drug encapsulation efficiency (EE) and mean size of protein loaded PLGA nanoparticles prepared by a W/O/W double emulsion method. From the Table 2 it was found that when the molecular weight of PLGA was higher the EE was enhanced and the particles were larger. The effect of high molecular weight PLGA on particle size seems to be independent of protein loadings but might be due to longer polymeric chains and their higher inherent viscosities. The use of PLGA with uncapped carboxylic end groups having a molecular weight of $34 \mathrm{kDa}$, The EE was $97 \%$, while the size was $271 \mathrm{~nm}$. This increase in $E E$ is due to an ionic interaction between the positively charged amino groups of proteins and the negative charges of the copolymer carboxylic acids [54]. A large particle size $1090 \mathrm{~nm}$ (i.e. so-called microparticles) was observed when the polymer concentration was doubled. This effect of polymer concentration on particle size might be due to the increased viscosity of the organic phase.

In $\mathrm{W} / \mathrm{O} / \mathrm{W}$ technique, proteins encapsulated into PLGA nano or microparticles are susceptible to denaturation or aggregation, oxidation, deamidation and cleavage, while creating the W/O primary emusion [55]. A large interface between the aqueous and organic phase is formed in this process, at which the protein may adsorb and denature. Protein stability may be enhanced if the protein is encapsulated as a solid rather than in solution. So, the modification of this method has been developed to solve those problems.

\section{Solid/oil/water (S/O/W) double emulsion solvent evaporation method}

Protein adsorption and denaturation at the aqueous/organic solvent interface is one of the major limitations for decreased protein bioactivity occurring during the encapsulation process. To protect protein from denaturation during formation of W/O emulsion, S/O/W method has been developed. This is because, proteins in the 
solid state are believed to maintain their bioactivity by drastically reducing conformational change in comparison to the large structural change found in the dissolved state [56]. In the S/O/W method, dehydrated protein powders are dispersed in the polymer solution to form the primary emulsion. Then the solid dispersion is introduced into a large volume of aqueous solution containing surfacting agent, such as PVA. It can be noted that making dispersion of protein particles in organic solvent is not so easy. Protein particle micronization is one of the major challenges in the $\mathrm{S} / \mathrm{O} / \mathrm{W}$ method which include lyophilization, spray drying, and spray freezedrying [57]. Spray freeze-drying collects atomized protein microdroplets in a frozen form and followed with the ice sublimation under reduced pressure. Thus, the temperature dependent protein denaturation and deactivation experienced in spray drying is circumvented. Nevertheless, one of the problems hampering the use of S/O/W technique is the low encapsulation efficiency of proteins. It is notable that encapsulation yield is an important parameter for cost-efficient production of microspheres containing expensive pharmaceutical proteins.

\section{Nanoprecipitation method}

Nanoprecipitation or solvent displacement method was introduced by Fessi and co-workers and has become a popular technique to prepare nanoparticles due to narrow size distribution, absence of shear stress, and absence of surfactants for amphiphilic polymers [41]. In this method, particles are formed spontaneously by precipitation and subsequent solidification of the polymer upon rapid solvent diffusion. The polymer and drug are dissolved in a water miscible organic solvent for example acetone or methanol. The solution is then poured under magnetic stirring into an aqueous solution which contains surfactant. Through rapid solvent diffusion, the nanoparticles are formed immediately. After that, the solvents are removed under reduced pressure. The mechanism of formation of NPs by this technique has been explained by the interfacial turbulence generated at the interface of the solvent and non-solvent. Thus, the process is often called solvent displacement or interfacial deposition.

\section{Emulsification solvent diffusion method}

In this technique, the organic solvent containing the dissolved polymer and the drug is emulsified in an aqueous surfactant solution (usually with PVA as a stabilizing agent) by using a highspeed homogenizer. Water is subsequently added under constant stirring to the OM emulsion system, thus causing phase transformation and outward diffusion of the solvent from the internal phase, leading to the nanoprecipitation of the polymer and the formation of colloidal nanoparticles. Finally, the solvent can be eliminated by vacuum steam distillation or evaporation. The most important fabrication step is solvent diffusion, in which the organic phase diffuses from the oil phase to outer water phase and the formed particles become hardened. The selection of the surfactants in the outer water phase is also crucial for successful fabrication.

\section{Salting-out method}

Salting out is another fabrication method for the preparation of PLGA nanoparticles. In this method, firstly PLGA is dissolved in a water miscible organic solvent such as tetrahydrofuran (THF) or acetone. Then, the oil phase is emulsified in an aqueous phase consisting of surfactant and salt of high concentration under strong shearing force by an overhead mechanical stirrer. Typically, the most commonly used salts are magnesium chloride hexahydrate or magnesium acetate tetrahydrate with a ratio of

Table 2: Effect of polymer type on encapsulation efficiency (EE) and mean size of protein-loaded PLGA nanoparticles ${ }^{\mathrm{a}}[15]$

\begin{tabular}{llllll}
\hline PLGA $^{\mathbf{b}}$ & $\begin{array}{l}\text { Polymer Mw by } \\
\text { GPC }(\mathbf{k D a})\end{array}$ & $\begin{array}{l}\text { Amount of } \\
\text { polymer }(\mathbf{m g})\end{array}$ & $\begin{array}{l}\text { Volume of inner } \\
\text { phase }(\mathbf{w})(\boldsymbol{\mu L})\end{array}$ & EE (\%) & Size $(\mathbf{n m})$ \\
\hline PLGA & 34 & 200 & 100 & 81 & 288 \\
PLGA & 12 & 200 & 100 & 89 & 207 \\
PLGA & 80 & 200 & 100 & 98 & 408 \\
PLGA-H & 34 & 200 & 100 & 97 & 271 \\
PLGA & 34 & 200 & 200 & 94 & 378 \\
PLGA & 34 & 400 & 200 & 84 & 1090 \\
\hline
\end{tabular}

${ }^{a}$ All batches were produced with ethyl acetate as organic solvent and at $1 \%$ of nominal DL; ${ }^{b}$ PLGA $=$ Resomer $^{\circledR}$ RG 502, RG 503 or RG 505; PLGA-H = Resomer ${ }^{\circledR}$ RG 503 with uncapped carboxylic end groups 
Table 3: Some marketed formulations of proteins based PLGA micro/nanooparticles [59]

\begin{tabular}{|c|c|c|c|}
\hline Product name & Active ingredient & Company & Application \\
\hline Lupron Depot@ & Leuprolide acetate & TAP & Prostate cancer \\
\hline Nutropin Depot® & Growth hormone & Genetech & Pediatric growth hormone deficiency \\
\hline Suprecur® MP & Buserelin acetate & Aventis & Prostate cancer \\
\hline Decapeptyl® & Triptorelin pamoate & Ferring & Prostate cancer \\
\hline Sandostatin LAR® Depot & Octreotide acetate & Novartis & Acromegaly \\
\hline Somatuline $®$ LA & Lanreotide & Ipsen & Acromegaly \\
\hline Trelstar TM Depot & Triptorelin pamoate & Pfizer & Prostate cancer \\
\hline Arestin $®$ & Minocycline & Orapharma & Periodontal disease \\
\hline Risperidal $®$ Consta ${ }^{\mathrm{TM}}$ & Risperidone & Johnson \& Johnson & Antipsychotic \\
\hline
\end{tabular}

1:3 (polymer to salt) [58]. The main difference between the emulsion diffusion and salting out method is that for the second one there is no solvent diffusion due to presence of salts. This is because, addition of pure water into the formed $\mathrm{O} / \mathrm{W}$ emulsion under magnetic stirring reduced the ionic strength of salt. At the same time, the hydrophilic organic solvents migrate from the oil phase to the aqueous phase resulting in the formation of nanoparticles. Finally, the salting out agent is removed by centrifugation.

\section{BIODEGRADABLE PLGA MICRO/ NANOPARTICLES AS PROTEIN DELIVERY SYSTEM}

Various therapeutic peptides and proteins encapsulated PLGA micro and nanoparticles have recently received much attention for their application of sustained release over an extended period. Since this technology provides unique advantages over traditional delivery approaches (e.g., improved drug efficacy and patient compliance), several formulations of proteins based on biodegradable micro/nanoparticles have already been marketed, as shown in Table 3 [59]. Since proteins are hydrophilic, high molecular weight macromolecules, and unstable to various detrimental environments, low encapsulation efficiency, incomplete and erratic release profiles are the most common features of controlled release protein delivery system using PLGA [32]. Denatured or aggregated protein species will not only be therapeutically inactive, but also may cause unpredictable side effects, such as immunogenicity or toxicity [60]. In the past two decades, many strategies have been investigated for the sustained, complete and native form of protein release from PLGA based micro and nanoparticles.

\section{Approaches to retain protein integrity in PLGA-based micro/nanoparticles}

The presence of water/solvent interface is one of the major factors for decreased protein bioactivity occurring during the emulsion method. In this emulsion preparing step, protein is exposed to large extent of water/organic interface, resulting in protein aggregation. The extent of protein aggregation depends on the nature of solvents. Dichlorometane (DCM) induces more protein aggregation than ethyl acetate [61]. The extent of protein aggregation during emulsification also depends on the methods of emulsification. It has been found from the study on the effect of different emulsification methods that sonication and vortex mixing generated slightly increased aggregation than homogenization [62].

\section{Role of viscous microenvironment in reducing protein denaturation}

A variety of stabilizing interface-active excipients such as sugars (e.g., trehalose, sorbitol) [61,63], polyethylene glycol (PEG) [64] are added into the internal protein solution to protect protein from aggregation as well as denaturation during emulsification. These excipients either reduce the protein adsorption at the water/organic solvent interface by competitive adsorption from additives (PEG, carrier proteins), or to accumulate at the water/organic solvent interface, thereby shielding proteins from degrading environment [9].

Jintian et al [65] prepared recombinant human erythropoietin (rhEPO) loaded PLGA microspheres using human serum albumin (HSA) as a stabilizer by a modified $\mathrm{S} / \mathrm{O} / \mathrm{W}$ technique. They claimed that the integrity of rhEPO was protected during the encapsulation process and 33 days release period from the polymeric 
matrices. Insulin encapsulated PLGA microspheres were prepared by a modified $\mathrm{O} / \mathrm{O}$ solvent evaporation method [66]. In this single was involved, and high sheering mixers (homogenizer or sonicator/or freeze-drying techniques) were not applied.

\section{Role of basic salts in reducing $\mathrm{pH}$-induced protein denaturation}

The degradation of biodegradable PLGA delivery matrices leads to generation of acidic oligomers (lactic/glycolic acids) which results in increase in acidity of microenvironment. This drop of $\mathrm{pH}$ in the microenvironment induces protein degradation. To overcome acidic microclimate within the device, basic salts such as $\mathrm{NaHCO}_{3}$, $\mathrm{ZnCO}_{3}, \mathrm{MgCO}_{3}$, or $\mathrm{Mg}(\mathrm{OH})_{2}$ has been found to be used as buffering agents into matrix to counteract acidic microenvironment. Zhu et al [67] reported that polymer microclimate has an acidic $\mathrm{pH}$ (less than 3 ) and it triggers unfolding of proteins like bovine serum albumin (BSA). To neutralize the acids liberated by the biodegradable lactic/glycolic acid polymers, they incorporated antacid $\mathrm{Mg}(\mathrm{OH})_{2}$ which increased the microclimate $\mathrm{pH}$ and prevented bovine serum albumin (BSA) structural losses and aggregation for over 1 month.

Rafi et al [68] reported that incorporation of HSA and $\mathrm{NaHCO}_{3}$ during particle formulation stabilized the recombinant human growth hormone ( $r-h G H)$ inside the PLGA microparticles. Three different zinc salts (i.e., zinc oxide, zinc carbonate, and zinc acetate) were incorporated in the preparation of insulin loaded PLGA microspheres [34]. Insulin secondary structure was unaltered due to the addition of zinc salts as compared to the formulation prepared without a zinc salt. They reported that formation of hexamers in presence of zinc salt was the major reason of improved insulin stability. In most cases, the buffering approach increased the stability of the released protein in vitro. Nevertheless, protein release profiles from PLGA microspheres were not fully controlled. So, the addition of other excipients or incorporation a salt in a different way is very important for maintaining protein stability and release kinetics.

\section{Role of functionalized hydrophilic polymers in reducing protein denaturation}

Due to the hydrophobic nature of PLGA, a slower release rate of recombinant human insulin-like growth factor-I (rhIGF) and of a somatostatin analogue have been observed $[69,70]$. So, the phase $\mathrm{O} / \mathrm{O}$ method insulin instability problems were minimized as no aqueous organic interface

use of promising new polymers that are more hydrophilic than PLGA have emerged. These polymers are more compatible with proteins; especially since they reduce protein absorption and favour homogeneous distribution within the matrix. Moreover, they increase water uptake within the microspheres. To enable a better water uptake and an easier diffusion of the protein and of the polymer degradation products out of the polymer, porous microspheres were prepared by a range of groups.

Biodegradable PLA or PLGA have been codissolved with various biocompatible hydrophilic or amphiphilic compounds in the encapsulation procedure to prevent acidic microclimate-induced instability reactions of proteins in degrading polymers. For instance, PLGA was blended with pore-forming PEG in order to enhance the release of EPO and insulin [71,72]. But, a burst and a steady rate of protein release in vitro were observed over 1 month. Complete release was not reached due to the presence of protein aggregates. Ghassemi et al [73] recently formulated microspheres from a novel functionalized hydrophilic aliphatic polyester, PLHMGA for reducing the $\mathrm{pH}$ induced aggregation of therapeutic proteins. From the in vitro release studies, they reported that the release of lysozyme was incomplete, likely due to aggregation of part of the encapsulated protein.

\section{ORAL DELIVERY FORMULATIONS OF PROTEIN/ PEPTIDE-LOADED PLGA NANOPARTICLES}

For the treatment of Type 1 diabetic patients, three subcutaneous injections are required daily to maintain the blood glucose level. The daily injection routine is inconvenient for patients due to pain, tenderness, local tissue necrosis, microbial infection and fear of hypoglycemia. Oral delivery of insulin is expected to overcome these problems. For many years various unsuccessful approaches have been developed for oral delivery of insulin $[74,75]$. The reasons for failure of oral delivery of bioactive macromolecules include the acidic environment of the stomach, rapid enzymatic degradation and the poor intestinal absorption [76]. Recently, Zhi et al [77] developed a two-stage delivery system for oral delivery of insulin. The system composed of $\mathrm{pH}$-sensitive hydroxypropyl methyl cellulose phthalate (HP 55) coated capsule containing insulin loaded PLGA and Eurdragit ${ }^{\circledR}$ RS (RS) 
cationic nanoparticles. In this study, insulin was protected from rapid enzymatic degradation in gastrointestinal $(\mathrm{GI})$ tract due to the coating of hard gelatin capsules by $\mathrm{pH}$ sensitive HP 55 . Whereas, PLGA/RS cationic nanoparticles were adhered to the intestinal mucosa resulting in a improved absorption of insulin across the intestinal epithelial cells. In another study, Sharma et al [78] developed antacid-insulin coencapsulated PLGA nanoparticles for oral delivery of insulin. They investigated both in vitrolin vivo studies of the prepared nanoparticles. From the in vitro test, they claimed that encapsulated insulin was well protected under simulated gastric and intestinal fluids. From the in vivo test, they showed that in diabetic rats, a $120 \mathrm{IU} / \mathrm{Kg}$ oral dose of insulin nanoparticles achieved an equivalent blood glucose lowering effect to a $20 \mathrm{IU} / \mathrm{Kg}$ subcutaneous dose of insulin solution. From this studies, they concluded that although oral delivery of insulin was achieved, further improvements is required to increase the $C_{\max }$ (maximum concentration attained in plasma) and to reduce the $T_{\max }$ (time to attain maximum plasma concentration) for successful oral delivery of protein drugs.

\section{CONCLUSION}

This review outlines the present research and development activities on PLGA and PLGAbased micro/nanoparticles as protein and peptide drug delivery devices. A deep understanding of the effects of fabrication methods, PLGA, surfactants and excipients nature is necessary for the formulation of protein loaded micro/nanoparticles with desired protein release profiles and structural integrity (i.e., bioactivity). Another important factor has to be considered in drug loading is protein encapsulation efficiency $(E E)$. Since protein drugs are usually extremely expensive, achieving the high EE is very essential to reduce the loss of expensive drug. The method of making protein drugs stable for extended period of time in the body condition has to be incorporated into the micro/nanoparticle preparation method. All the above mentioned factors need to be understood for successful development of long-term protein delivery systems using biodegradable PLGA micro or nanoparticles. Although many advances have been made for formulation of successful protein delivery devices, much work still remains before proteins can be used as a therapeutic molecule in PLGA based drug delivery systems.

\section{ACKNOWLEDGEMENT}

Authors would like to thank International Islamic University Malaysia for providing financial assistance during this work through the project No. EDW B 12-330-0808.

\section{REFERENCES}

1. Soppimath KS, Aminabhavi TM, Kulkarni AR, Rudzinski WE. Biodegradable polymeric nanoparticles as drug delivery devices. J. Control. Release 2001; 70: 1-20.

2. Karen GC, Ann MS, Juan CA, Patricia DJ, Henry RC, Carlos JB, Kai G. Non-aqueous encapsulation of excipient-stabilized spray-freeze dried BSA into poly(lactide-co-glycolide) microspheres results in release of native protein. J. Control. Release 2001; 76: 199-208.

3. Bittner B, Ronneberger B, Zange R, Volland C, Anderson JM, Kissel T. Bovine serum albumin loaded poly(lactide-co-glycolide) microspheres: the influence of polymer purity on particle characteristics. J. Microencapsul. 1998; 15: 495-514.

4. Johansen P, Men Y, Audran R, Corradin G, Merkle HP, Gander $B$. Improving stability\&release kinetics of microencapsulated tetanus toxoid by coencapsulation of additives. Pharm. Res. 1998; 15: 1103-1110.

5. Athanasiou KA, Niederauer GG, Agrawal CM. Sterilization, toxicity, biocompatibility and clinical applications of polylactic acid /polyglycolic acid copolymers. Biomaterials 1996; 17: 93-102.

6. Göpferich A. Mechanisms of polymer degradation and erosion. Biomaterials 1996; 17: 103-114.

7. Gilding DK, Reed AM. Biodegradable polymers for use in surgery. Polyglycolic/poly(lactic acid) homo- and copolymers: 1. Polymer 1979; 20: 1459-1464.

8. Crotts G, Tae GP. Protein delivery from poly(lactic-coglycolic acid)biodegradable microspheres: release kinetics and stability issues. J. Microencapsul. 1998; 15: 699-713.

9. Eun SL, Min JK, Hyeok L, Jung JK. Stabilization of protein encapsulated in poly(lactide-co-glycolide) microspheres by novel viscous S/W/O/W method. Int. J. Pharm. 2007; 331: 27-37.

10. Dolores B, Mari'a JA. Protein encapsulation and release from poly(lactide-co-glycolide) microspheres: effect of the protein and polymer properties and of the coencapsulation of surfactants. Eur. J. Pharm. Biopharm. 1998; 45: 285-294.

11. Tia E, Jichao K, Steven PS, John FC. BSA degradation under acidic conditions: a model of protein instability during release from PLGA delivery systems. J. Pharm. Sci. 2006; 95: 1626-1639.

12. Jichao K, Steven PS. Comparison of the effects of $\mathrm{Mg}(\mathrm{OH}) 2$ and sucrose on the stability of bovine serum albumin encapsulated in injectable poly $(D, L-$ 
lactide-co-glycolide) implants. Biomaterials. 2002; 23 : 239-245

13. Jayanth $P$, Manisha MD, Sanjeeb $K S$, Wenxue $M$, Sudhir SC, Gordon LA, Robert JL, Vinod L. Polymer degradation and in vitro release of a model protein from poly(D,L-lactide-co-glycolide) nano and microparticles. J. Control. Release. 2003; 92: 173187.

14. Ogawa $Y$, Yamamoto $M$, Takada $S$, Okada $H$, Shimamoto $T$. Controlled-release of leuprolide acetate from polylactic acid or copoly(lactic/glycolic) acid microcapsules: influence of molecular weight and copolymer ratio of polymer. Chem. Pharm. Bull. 1988; 36: 1502-1507.

15. Bilati U, Allemann E, Doelker E. Poly(D,L-lactide-coglycolide) protein-loaded nanoparticles prepared by the double emulsion method-processing and formulation issues for enhanced entrapment efficiency. J. Microencapsul. 2005; 22: 205-214.

16. Crotts G, Tae GP. Stability and release of bovine serum albumin encapsulated within poly(D,L-lactide-coglycolide) microparticles. J. Control. Release. 1997; 44: 123-134.

17. Jalil R, Nixon JR. Microencapsulation using poly (L-lactic acid) III: Effect of polymer molecular weight on the microcapsule properties. J. Microencapsul. 1990; 7: 41-52.

18. Park TG. Degradation of poly(D,L-lactic acid) microspheres: effect of molecular weight. J. Control. Release 1994; 30: 161-173.

19. Li S. Hydrolytic degradation characteristics of aliphatic polyesters derived from lactic and glycolic acids. J. Biomed. Mater. Res. 1999; 48: 342-353.

20. Walter E, Dreher D, Kok M, Thiele L, Kiama SG, Gehr P, Merkle HP. Hydrophilic poly(DL-lactide-co-glycolide) microspheres for the delivery of DNA to humanderived macrophages and dendritic cells. J. Control. Release 2001; 76: 149-168.

21. Luan $X$, Bodmeier $R$. Influence of the poly(lactide-coglycolide) type on the leuprolide release from in situ forming microparticle systems. J. Control. Release 2006; 110: 266-272.

22. Visscher GE, Robison RL, Mauling $H V$, et al. Biodegradation of and tissue reaction to $50: 50$ poly(d,l-lactide-co-glycolide) microcapsules. J. Biomed. Mater. Res. 1985; 19: 349-365.

23. Visscher GE, Robison RL, Maulding HV, Fong JW, Pearson JE Argentieri GJ. Biodegradation of and tissue reaction to poly(dl-lactide) microcapsules. J. Biomed. Mater. Res. 1986; 20: 667-676.

24. Jamshidi $K$, Hyon SH, Ikada Y. Thermal characterization of polylactides. Polymer 1988; 29: 2229-2234.

25. Mu L, Feng SS. A novel controlled release formulation for the anticancer drug paclitaxel (Taxol (R)): PLGA nanoparticles containing vitamin E TPGS. J. Control. Release 2003; 86: 33-48.

26. Schnieders J, Gbureck U, Thull R, Kissel T. Controlled release of gentamicin from calcium phosphate-
Poly(lactic acid-co-glycolic acid) composite bone cement. Biomaterials 2006; 27: 4239-4249.

27. Prior S, Gamazo C, Irache JM., Merkle HP, Gander B. Gentamicin encapsulation in PLA/PLGA microspheres in view of treating Brucella infections. Int. J. Pharm. 2000; 196: 115-125.

28. Prior S, Gander B, Irache JM, Gamazo C. Gentamicinloaded microspheres for treatment of experimental Brucella abortus infection in mice. J Antimicrob Chemother 2005; 55: 1032-1036.

29. Cleland JL, Mac A, Boyd B, Yang J, Duenas ET, Yeung $D$, Brooks D, Hsu C, Chu H, Mukku V, et al. The stability of recombinant human growth hormone in poly(lactic-co-glycolic acid) (PLGA) microspheres. Pharm. Res. 1997; 14: 420-425.

30. Okada $H$. One- and three-month release injectable microspheres of the $\mathrm{LH}-\mathrm{RH}$ superagonist leuprorelin acetate. Adv. Drug Deliv. Rev. 1997; 28: 43-70.

31. Murty SB, Thanoo BC, Wei Q, DeLuca PP. Impurity formation studies with peptide-loaded polymeric microspheres: Part I. In vivo evaluation. Int. J. Pharm. 2005; 297: 50-61.

32. Jiang G, Byung HW, Feirong $K$, Jagdish S, Patrick PD. Assessment of protein release kinetics, stability and protein polymer interaction of lysozyme encapsulated poly(D,L-lactide-co-glycolide) microspheres. J. Control. Release 2002; 79: 137-145.

33. Aleksandra $P$, Katerina G, Kristina M, Marija G, Maja S, Emilija IJ, Maja C. Poly(lactide-co-glycolide) microparticles as systems for controlled release of proteins-Preparation and characterization. Acta Pharm. 2004; 54: 215-229.

34. Chandrasekar $M$, Jagdish S. Insulin loaded PLGA microspheres:Effect of zinc salts on encapsulation, release, and stability. J. Pharm. Sci. 2009; 98: 529542.

35. Thillaye BO, Boullay D, Saffon N, Diehl JP, Martin-Vaca $B$, Bourissou D. Organo-catalyzed ring-opening polymerization of 1,4-dioxane-2,5-dione deriving from glutamic acid. Biomacromolecules 2010; 11: 19211929.

36. Pounder RJ, Dove AP. Synthesis and organocatalytic ring-opening polymerization of cyclic esters derived from L-malic acid. Biomacromolecules 2010; 11: 1930-1939.

37. Yamaoka T, Hotta Y, Kobayashi K, Kimura Y. Synthesis and properties of malic acid-containing functional polymers. Int. J. Biol. Macromol. 1999; 25: 265-271.

38. Leemhuis M, Nostrum CF, Kruijtzer JAW, Zhong ZY, ten Breteler MR, Dijkstra PJ, Feijen J, Hennink WE. Functionalized poly(a-hydroxy acid)s via ringopening polymerization: toward hydrophilic polyesters with pendant hydroxyl groups. Macromolecules 2006; 39: 3500-3508.

39. Leemhuis M, Kruijtzer JAW, Nostrum CF, Hennink WE. In vitro hydrolytic degradation of hydroxyl-functionalized poly(a-hydroxy acid)s. Biomacromolecules 2007; 8: 2943-2949.

Trop J Pharm Res, July 2014; 13(7):1188 
40. Julienne MC, Alonso MJ, Gomez Amoza JL, Benoit JP. Preparation of poly(DL-lactide/glycolide) nanoparticles of controlled particle size distribution:application of experimental designs. Drug Dev. Ind. Pharm. 1992; 18: 1063-1077.

41. Fessi H, Puisieux F, Devissaguet JP, Ammoury N, Benita S. Nanocapsule formation by interfacial polymer deposition following solvent displacement. Int. J. Pharm. 1989; 55: R1-R4.

42. Quintanar-Guerrero $D$, Fessi $H$, All'emann $E$, et al. Influence of stabilizing agents and preparative variables on the formation of poly(d,I-lactic acid) nanoparticles by an emulsification-diffusion technique. Int. J. Pharm. 1996; 143: 133-141.

43. Allemann E, Leroux JC, Gurny R, Doelker E. In vitro extended-release properties of drug-loaded poly(DLlactic acid) nanoparticles produced by a salting-out procedure. Pharm. Res. 1993; 10: 1732-1737.

44. Jung $T$, Breitenbach A, Kissel T. Sulfobutylated poly(vinyl alcohol)-graft-poly(lactide-co-glycolide)s facilitate the preparation of small negatively charged biodegradable nanospheres. J. Control. Release 2000; 67: 157-169.

45. Dreis S, Rothweiler F, Michaelis M, Cinatl J, Kreuter J, Langer $K$. Preparation, characterisation and maintenance of drug efficacy of doxorubicin-loaded human serum albumin (HSA) nanoparticles. Int. J. Pharm. 2007; 341: 207-214.

46. Ruan G, Feng SS, Li QT. Effects of material hydrophobicity on physical properties of polymeric microspheres formed by double emulsion process. J. Control. Release 2002; 84: 151-160.

47. Hariharan S, Bhardwaj V, Bala I, Sitterberg J, Bakowsky U, Kumar M. Design of estradiol loaded PLGA nanoparticle formulations:A potential oral delivery system for hormone theraphy. Pharm. Res. 2006; 23: 184-195.

48. Astete CE, Kumar CSSR, Sabliov CM. Size control of poly(d,I-lactide-co-glycolide) and poly(d,I-lactide-coglycolide)-magnetite nanoparticles synthesized by emulsion evaporation technique. Colloids Surf. A Physicochem. Eng. Asp. 2007; 299: 209-216.

49. Sahana DK, Mittal G, Bhardwaj V, Kuamr M. PLGA nanoparticles for oral delivery of hydrophobic drugs:Influence of organic solvent on nanoparticle formation and release behavior in vitro and in vivo using estradiol as a model drug. J. Pharm. Sci. 2008; 97: 1530-1542.

50. Zhang ZP, Lee SH, Feng SS. Folate-decorated poly(lactide-co-glycolide)-vitamin E TPGS nanoparticles for targeted drug delivery. Biomaterials; 2007; 28: 1889-1899.

51. Yang YY, Chung TS, Ng NP. Morphology, drug distribution, and in vitro release profiles of biodegradable polymeric microspheres containing protein fabricated by double-emulsion solvent extraction/evaporation method. Biomaterials 2001; 22: 231-241.
52. Sah HK, Toddywala R, Chien YW. Biodegradable microcapsules prepared by a W/O/W technique: effects of shear force to make a primary W/O emulsion on their morphology and protein release. $\mathrm{J}$. Microencapsul. 1995; 12: 59-69.

53. Yang YY, Chia HH, Chung TS. Effect of preparation temperature on the characteristics and release profiles of PLGA microspheres containing protein fabricated by double-emulsion solvent extraction/evaporation method. J. Control. Release 2000; 69: 81-96.

54. Okada Y, Yamamoto $M$, Heya $T$, Inoue $Y$, Kamei $S$, Ogawa $Y$, Toguchi $H$. Drug delivery using biodegradable microspheres. J. Control. Release 1994; 28: 121-129.

55. Weert MVD, Hoechstetter J, Hennink WE, Crommelin DJ. The effect of a water/organic solvent interface on the structural stability of lysozyme. J. Control. Release 2000; 68: 351-359.

56. Castellanos IJ, Crespo R, Griebenow K. Poly(ethylene glycol) as stabilizer and emulsifying agent: a novel stabilization approach preventing aggregation and inactivation of proteins upon encapsulation in bioerodible polyester microspheres. J. Control. Release 2003; 88: 135-145.

57. Wang J, Chua KM, Wang CH. Stabilization and encapsulation of human immunoglobulin $G$ into biodegradable microspheres. J. Colloid. Interface Sci. 2004; 271: 92-101.

58. Eley JG, Pujari VD, McLane J. Poly(lactide-co-glycolide) nanoparticles containing coumarin-6 for suppository delivery: in vitro release profile and in vivo tissue distribution. Drug Dlivery 2004; 11: 255-261.

59. Raghavendra CM, Ramesh BV, Rangaswamy V, Pradip $P$, Tejraj MA. Nano/micro technologies for delivering macromolecular therapeutics using poly(D,L-lactideco-glycolide) and its derivatives. J. Control. Release 2008; 125: 193-209.

60. Jiskoot $W$, Schie VR, Carstens M, Schellekens $H$. Immunological risk of injectable drug delivery systems. Pharm. Res. 2009; 26: 1303-1314.

61. Cleland JL, Jones AJ. Stable formulations of recombinant human growth hormone and interferon-gamma for microencapsulation in biodegradable microspheres. Pharm. Res. 1996; 13: 1464-1475.

62. Morlock MK, Winter HG, Kissel T. Microencapsulation of rh-erythropoietin, using biodegradable poly $(D, L-$ lactide-co-glycolide): protein stability and the effects of stabilizing excipients. Eur. J. Pharm. Biopharm. 1997; 43: 29-36.

63. Cleland JL, Duenas ET, Park A, Daugherty A, Kahn J, Kowalski J, Cuthbertson A. Development of poly (D,Llactide-co-glycolide) microsphere formulations containing recombinant human vascular endothelial growth factor to promote local angiogenesis. J. Control. Release 2001; 72: 13-24. 
64. Manish D, Tae Gwan P. Pegylation enhances protein stability during encapsulation in PLGA microspheres. J. Control. Release 2001; 73: 233-244.

65. Jintian H, Meiyan F, Xianglian Z, Shufen M, Yang J, Ying $W$, Hongxia Z. Stabilization and encapsulation of recombinant human erythropoietin into PLGA microspheres using human serum albumin as a stabilizer. Int. J. Pharm. 2011; 416: 69- 76.

66. Emami J, Hamishehkar $H$, Najafabadi AR, Gilani K, Minaiyan M, Mahdavi $H$, Nokhodchi A. A novel approach to prepare insulin-loaded poly(lactic-coglycolic acid) microcapsules and the protein stability study. J. Pharm. Sci. 2009; 98: 1712-1731.

67. Zhu G, Hallery SR, Schwendemem SP. Stabilisation of proteins encapsulated in injectable poly(lactide-coglycolide) polymers. Nat. Biotech. 2000; 18: 52-57.

68. Rafi M, Surinder MS, Vibhu K, Anish CK, Amulya KP. Controlled release of bioactive recombinant human growth hormone from PLGA microparticles. J. Microencapsul. 2010; 27: 552-560.

69. Blanco-Prieto MJ, Campanero MA, Besseghir K, Heimgatner F, Gander B. Importance of single or blended polymer types for controlled in vitro release and plasma levels of a somatostatin analogue entrapped in PLA/PLGA microspheres. J. Control. Release 2004; 96: 437-448.

70. Lam XM, Duenas ET, Daugherty AL, Levin N, Cleland JL. 2000. Sustained release of recombinant human insulin-like growth factor-I for treatment of diabetes. J. Control. Release 2000; 67: 281-292.

71. Morlock M, Kissel T, Li YX, Koll H, Winter G. Erythropoietin loaded microspheres prepared from biodegradable LPLG-PEO-LPLG triblock copolymers: protein stabilization and in-vitro release properties. J. Control. Release 1998; 56: 105-115.

72. Yeh MK. The stability of insulin in biodegradable microparticles based on blends of lactide polymers and polyethylene glycol. J. Microencapsul. 2000; 17: 743-756.

73. Ghassemi $A H$, van Steenbergen MJ, Talsma $H$, van Nostrum CF, Jiskoot W, Crommelin DJA, Hennink $W E$. Preparation and characterization of protein loaded microspheres based on a hydroxylated aliphatic polyester, poly(lactic-co-hydroxymethyl glycolic acid). J. Control. Release 2009; 138: 57-63.

74. Still J. Development of oral insulin: progress and current status. Diabetes Metab. Res. Rev. 2002; 18: S29S37.

75. Khafagy ES, Morishita M, Onuki Y, Takayama K. Current challenges in non-invasive insulin delivery systems: a comparative review. Adv. Drug Deliv. Rev. 2007; 59: 1521-1546.

76. Stoll BR, Batycky RP, Leipold HR, Milstein S, Edwards $D A$. A theory of molecular absorption from the small intestine. Chem. Eng. Sci. 2000a; 55: 473-489.

77. Zhi MW, Liying Z, Xin DG, Wei J, Li L, Yu Q, Kathy QL, Li JZ. HP55-coated capsule containing PLGA/RS nanoparticles for oral delivery of Insulin. Int. J. Pharm. 2012; 425: 1-8.

78. Sharma G, van der Walle CF, Ravi Kumar MNV. Antacid co-encapsulated polyester nanoparticles for peroral delivery of insulin: Development, pharmacokinetics, biodistribution and pharmacodynamics. Int. J. Pharm. 2013; 440: 99-110. 